\title{
Damage evaluation during installation of geosynthetics used in asphalt pavements
}

\author{
I. Gonzalez-Torre ${ }^{1}$, M. A. Calzada-Perez ${ }^{2}$, A. Vega-Zamanillo ${ }^{3}$ and D. Castro-Fresno ${ }^{4}$ \\ ${ }^{1}$ PhD Candidate, Construction Technology Applied Research Group (Giteco), University of Cantabria, \\ Avda de Los Castros s/n, 39005, Santander, Spain, Telephone: +34 942 20 3943; Telefax: \\ +34942 2017 03. Email: irene.gonzaleztorre@gmail.com \\ ${ }^{2}$ Professor, Group of Roads (GCS), University of Cantabria, Avda de Los Castros s/n, 39005, Santander, \\ Spain, Telephone: +34942201769; Telefax:+34942201703; E-mail: calzadama@unican.es \\ ${ }^{3}$ Professor, Group of Roads (GCS), University of Cantabria, Avda de Los Castros s/n, 39005, Santander, \\ Spain, Telephone: +34942201753; Telefax:+34942201703; E-mail: vegaa@unican.es \\ ${ }^{4}$ Professor, Construction Technology Applied Research Group (Giteco), University of Cantabria, Avda de \\ Los Castros s/n, 39005, Santander, Spain, Telephone: +34 94220 20 53; Telefax: +34 9422017 03; \\ E-mail: castrod@unican.es
}

Received 1 April 2014, revised 20 August 2014, accepted 13 October 2014

\begin{abstract}
Geosynthetics are commonly used as anti-reflective cracking systems in asphalt pavements. The rehabilitation design methods use the characteristics of as-received geosynthetics as inputs. However, these materials undergo physical damage during their installation due to mechanical and thermal loads which currently are not taken into account in the design processes. These loads can produce a reduction in geosynthetic strength and therefore, it is necessary to know the secant modulus after installation in order to improve the pavement design incorporating these materials. The secant modulus of a material indicates its initial stiffness. This paper describes an experimental study of damage due to installation of five different geosynthetics using three different procedures: (i) mechanical damage induced in the laboratory considering the action of aggregates, (ii) in situ mechanical and thermal damage due to actual installation in a test section, and (iii) a new mechanical and thermal damage experimental test developed with the aim of reproducing the real installation conditions. The main results of the study indicate that the obtained secant modulus of the tested geosynthetics reduced after applying the three damage procedures, and the loss of properties differed depending on the type and constitutive material and on the applied damage procedure.
\end{abstract}

KEYWORDS: Geosynthetics, Installation damage, Anti-reflective cracking, Mechanical properties, Secant modulus

REFERENCE: Gonzalez-Torre, I., Calzada-Perez, M. A., Vega-Zamanillo, A. \& Castro-Fresno, D. (2014). Damage evaluation during installation of geosynthetics used in asphalt pavements. Geosynthetics International, 21, No. 6, 377-386. [http://dx.doi.org/10.1680/gein.14.00025]

\section{INTRODUCTION}

One of the problems that affect roads is damage due to reflective cracking. This problem is very common in semi-rigid pavements, and involves the propagation of cracks from a base layer which is already cracked (usually a cement-treated layer) to the surface of a bituminous layer that is placed as rehabilitation (Cleveland et al. 2002). When the treatment applied to solve the problem is the spreading of a hot mix asphalt (HMA), the cracks rise to the surface over a short period. This is mainly due to horizontal and vertical movements caused by traffic loads combined with temperature variations. Localised bending and shear stresses appear on the existing crack and cause further development of cracks (Nunn 1989).

In this context, there are several techniques to rehabilitate cracked pavements, including the use of geosynthetics (e.g. geotextiles, geogrids and geocomposites) acting as anti-reflective cracking systems. It has been shown that these materials delay crack propagation (Zamora-Barraza et al. 2011; Canestrari et al. 2013) and that the grid tensile strength increases the mechanical properties of reinforced pavement systems (Pasquini et al. 2013). Zamora-Barraza et al. (2011) also stated that the higher the secant modulus of the geosynthetics, the better their anti-reflective behaviour. Geosynthetics are placed under the overlay layer so 
they must retain the continuity between pavement layers and ensure correct bonding to them (Zamora-Barraza et al. 2010). Therefore, the secant modulus is the key variable that must be taken into account in geosynthetics that are acting as anti-reflective cracking systems, and a geosynthetic only reinforces the pavement if it is bonded to the pavement layers.

The mechanical properties of geosynthetics, such as the elastic modulus, are key factors in the design of pavement rehabilitation solutions. It is important to know their mechanical behaviour when acting as anti-reflective cracking systems. Numerical models using finite element analysis (FEA) and employing multi-layer systems for mechanical-empirical pavement design use the elastic modulus of the materials as inputs. However, the elastic modulus does not represent the real behaviour of geosynthetics. Moreover, the characteristics of as-received geosynthetics are well known through the data supplied by the manufacturers or obtained by laboratory tests, and they are directly included in the design models (Siriwardane et al. 2010; Górszczyk and Gaca 2012). However, they do not represent the real behaviour of the geosynthetics because any effects that occur during installation are not taken into account. Installation is an aggressive process and when a geosynthetic is laid under a HMA layer, at approximately $150^{\circ} \mathrm{C}$, deterioration occurs for two reasons: first, the mechanical effect produced by spreading and compacting the mixture, and second, the thermal effect due to the high temperatures that occur during placement of the mixture.

There have been a few studies that investigated the potential installation damage to geosynthetics. Norambuena-Contreras et al. (2009) studied the effect of high temperature on the behaviour of geosynthetics and showed that materials such as polypropylene, which is very common in geosynthetics, suffer significant deterioration when the temperature is increased up to $140^{\circ} \mathrm{C}$. This is because the material is a thermoplastic polymer and it becomes soft above a specific temperature. Therefore, any HMA will significantly damage the geosynthetic material during the installation process, and an initial variation of the mechanical properties of geosynthetics can be expected.

Furthermore, Correia and Bueno (2011) studied the effect produced on geosynthetics by a bituminous emulsion. In this case, different nonwoven geotextiles made of polyester and polypropylene and a nonwoven polypropylene geotextile reinforced with glass fibre filaments were impregnated with a bitumen emulsion and then subjected to tensile testing, with the aim of evaluating the variation between the secant modulus with and without emulsion. The results showed that the application of an emulsion produced an increase in the initial geotextile strength and stiffness, and so theoretically its behaviour in terms of anti-reflective cracking will improve. However, these results do not consider the damage produced due to the installation process and so these conclusions can be considered debatable.

On the other hand, there have been studies applied to soil areas (Allen and Bathurst 1994; Hufenus et al. 2005,
2006; Benson et al. 2010; Bathurst et al. 2011), that have evaluated the damage to geosynthetics by studying the reduction in their mechanical properties when they are used as soil reinforcements. However, in these studies, the effect of high temperatures was not taken into account. These tests simply evaluated the action of an angular aggregate spread and compacted over the geosynthetics. There was a loss of resistant properties in all cases, which varied with the type and the materials that the geosynthetic was made of. In addition, some authors have also evaluated the deterioration that may occur due to transport, handling and placement of geosynthetics used as soil reinforcement. In this regard, Rosete et al. (2012) showed that there was a substantial loss of strength in the geosynthetics due to deterioration during installation. This was simulated in the laboratory by using a standard test according to ISO 10722:2007 (ISO 2007). Meanwhile, Paula et al. (2012) studied the in situ damage during installation of a polyester geogrid subjected to different energies of compaction. More recently, Pinho-Lopes and Lopes (2013) compared data from field installation trials of geosynthetics and laboratory tests (according to ENV ISO 10722-1:1998 (ISO 1998)). The results showed a loss of tensile strength which depends on the energy and the type of soil employed during the procedure, as well as the type of geosynthetic.

Furthermore, another aspect of the deterioration of geosynthetics included in the current norms is the longterm behaviour (e.g. creep test). This behaviour is especially taken into account for applications in which geosynthetics act as soil reinforcements. Some authors such as Jeon et al. (2006) and Cho et al. (2006) have studied the loss of creep resistance undergone by geogrids during the standard test. Results indicated that the creep resistance loss is very low.

The actual behaviour of geosynthetics as anti-reflective cracking systems clearly depends on the resistant properties and behaviour during their lifetime. Furthermore, it should be noted that there are no standards and procedures concerning the evaluation of the damage that may occur during installation of geosynthetics under HMA layers. Finally, the secant modulus is the main mechanical variable that must be measured in order to have some knowledge of how the geosynthetic will respond as an anti-reflective cracking system.

\section{OBJECTIVE}

The objective of this paper was to experimentally evaluate damage during installation of geosynthetics used as antireflective cracking systems under a dense HMA layer. For this purpose, five different geosynthetics commonly used in asphalt pavements were evaluated by using three different procedures: (i) a mechanical damage procedure induced in the laboratory considering the action of aggregates, (ii) an in situ mechanical and thermal damage procedure under the actual installation, and (iii) a new mechanical and thermal damage experimental procedure developed with the aim of reproducing the real installation conditions. 


\section{MATERIALS}

Five different geosynthetics, one asphalt mixture and one bituminous emulsion were used in the present study. The geosynthetics used were: a polypropylene nonwoven geotextile (G1), a polypropylene nonwoven geotextile reinforced with glass fibre filaments $(\mathrm{G} 2)$, a polyester geogrid with a polypropylene nonwoven light geotextile (G3), a polyvinyl alcohol geogrid with a polypropylene nonwoven light geotextile (G4) and a polypropylene stiff monolithic geogrid with a polypropylene/polyester fabric (G5). Table 1 presents their main physical properties and Figure 1 shows the theoretical scheme of their morphological structure. These physical properties were considered as reference values. The specimens used to simulate the pavement layers were manufactured using an AC16 Surf 50/70 dense asphalt mixture, according to EN 13108-1: 2006/AC: 2008 (BSI 2008). Finally, the bituminous emulsion used as tack coat was a C69 B3, with a residual bitumen content of 69\% as reflected in EN 13808:2005 (BSI 2005).

\section{METHODOLOGY}

\subsection{Characterisation tensile test}

To determine the initial mechanical properties (as-received properties) of the studied geosynthetics a characterisation of their tensile behaviour was carried out according to ISO 10319:2008 (ISO 2008). Tables 2 and 3 present the obtained mechanical properties.

\subsection{Reference contrast tensile test}

To evaluate and contrast the residual properties after the different damage procedures, wide-width tensile tests according to ISO 10319:2008 (ISO 2008) were employed as reference tests. Thus, five standardised samples of each geosynthetic were tested using flat clamps in all cases. The characteristics measured were the tensile strength and the secant modulus under a deformation of $2 \%$. The deformations were measured in the centre of the samples by a light extensometer. To ensure that all materials had been kept under the same storage conditions, the samples

Table 1. Characteristics of the geosynthetics and required amount of bitumen

\begin{tabular}{|l|c|c|c|c|}
\hline Geosynthetic & Mass $\left(\mathrm{g} / \mathrm{m}^{2}\right)$ & Thickness $(\mathrm{mm})$ & $\begin{array}{c}\text { Grid size } \\
(\mathrm{mm} \times \mathrm{mm})\end{array}$ & $\begin{array}{c}\text { Working maximum } \\
\text { temperature }\left({ }^{\circ} \mathrm{C}\right)\end{array}$ \\
\hline G1 & 140 & 1.2 & - & 165 \\
G2 & 430 & 1.8 & $40 \times 40$ & 400 \\
G3 & 270 & 1.9 & $40 \times 40$ & 1.10 \\
G4 & 160 & 1.5 & $40 \times 40$ & 190 \\
G5 & 220 & 4.1 & $65 \times 65$ & 0.10 \\
\end{tabular}

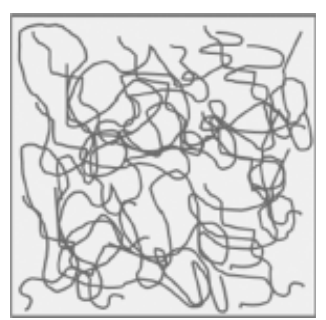

(a)

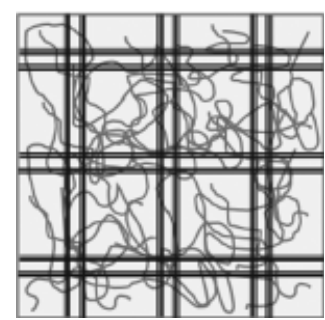

(b)

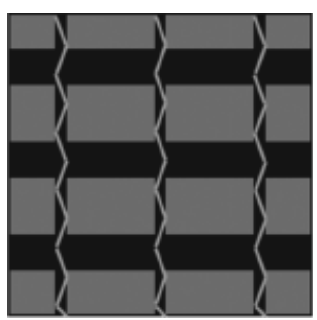

(c)

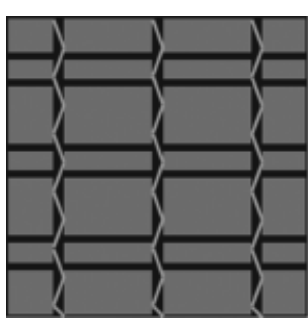

(d)

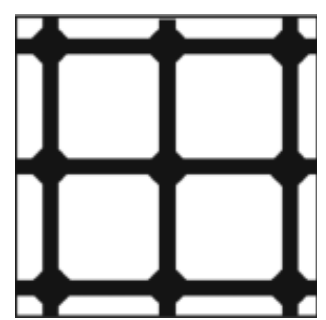

(e)

Figure 1. Structure of the geosynthetics: (a) G1, nonwoven geotextile; (b) G2, nonwoven geotextile reinforced with glass fibre filaments; (c) G3 and (d) G4, geogrid bonded to a light nonwoven geotextile and (e) G5, stiff monolithic geogrid bonded to a fabric

Table 2. Tensile strength obtained from wide-width tensile tests (values in $\mathrm{kN} / \mathrm{m}$ ).

\begin{tabular}{|c|c|c|c|c|}
\hline \multirow[t]{2}{*}{ Geosynthetic } & \multicolumn{4}{|c|}{ Applied test } \\
\hline & Characterisation (as-received) & $\begin{array}{c}\text { Mechanical damage by } \\
\text { aggregates }\end{array}$ & Real installation by HMA & New installation by HMA \\
\hline G1 & $10.1 \pm 1.1$ & $9.0 \pm 1.5(17)$ & $5.1 \pm 2.6(51)$ & $3.8 \pm 1.7(45)$ \\
\hline $\mathrm{G} 2$ & $57.5 \pm 4.8(8)$ & $12.1 \pm 1.5(12)$ & $10.4 \pm 5.1$ & $5 \pm 0.1(2)$ \\
\hline G3 & $51.2 \pm 2.1$ & $46.2 \pm 0.6(1)$ & $27.6 \pm 2.9(11)$ & $32.2 \pm 6.6(21)$ \\
\hline G4 & $30.8 \pm 0.7(2)$ & $30.5 \pm 1.9(6)$ & $16.8 \pm 2.3(14)$ & $19.5 \pm 0.6$ \\
\hline G5 & $27.2 \pm 0.4(2)$ & $27.2 \pm 0.4(2)$ & $22.5 \pm 4.1$ & $22.8 \pm 0.27$ \\
\hline
\end{tabular}

Note: the presented values are average value \pm std. deviation (coefficient of variation in \%). 
Table 3. Secant modulus under a deformation of $2 \%$ obtained from wide-width tensile tests (values in $\mathrm{kN} / \mathrm{m}$ )

\begin{tabular}{|l|c|c|c|c|}
\hline \multirow{2}{*}{ Geosynthetic } & \multicolumn{4}{|c|}{ Applied test } \\
\cline { 2 - 5 } & Characterisation (as-received) & $\begin{array}{c}\text { Mechanical damage by } \\
\text { aggregates }\end{array}$ & Real installation by HMA & New installation by HMA \\
\hline G1 & $37 \pm 2.6(7)$ & $29 \pm 3.2(11)$ & $14 \pm 3.8(27)$ & $25 \pm 7.1(28)$ \\
G2 & $2811 \pm 293.2(10)$ & $565 \pm 87.6(16)$ & $555 \pm 251.7(45)$ & $67 \pm 17.1(26)$ \\
G3 & $471 \pm 12.5(3)$ & $487 \pm 24.9(5)$ & $260 \pm 105.8(41)$ & $362 \pm 90.2(25)$ \\
G4 & $429 \pm 12.3(3)$ & $439 \pm 22.2(5)$ & $390 \pm 176.9(45)$ & $271 \pm 98.3(36)$ \\
G5 & $472 \pm 25.5(5)$ & $478 \pm 29.3(6)$ & $445 \pm 22.0(5)$ & $448 \pm 4.9(1)$ \\
\hline
\end{tabular}

Note: the presented values are average value \pm std. deviation (coefficient of variation in \%).

were conditioned for a minimum of $24 \mathrm{~h}$ at a temperature of $20^{\circ} \mathrm{C}$ and $65 \%$ humidity before the tensile tests.

As mentioned above, the most important result is the value of the secant modulus, which indicates the initial stiffness of a geosynthetic. This value is calculated as the slope of the stress-strain curves under a specific deformation value and is commonly calculated at deformations of 2, 5 and 10\%. Geosynthetics placed as anti-reflective cracking systems in a pavement are unlikely to ever undergo large deformations (more than 1-2\%), otherwise the pavement would be completely broken. In fact, it has been demonstrated by Zamora-Barraza et al. (2011) that crack propagation begins when the strain is approximately $1.2 \%$ at the bottom of the overlay layer. They concluded that geosynthetics would work in this range of deformation.

\subsection{Mechanical damage by aggregates test}

A test based on ISO 10722:2007 (ISO 2007) was carried out with the objective of evaluating the mechanical damage when only considering the action of aggregates on geosynthetics. The test consisted of inducing some artificial mechanical damage under laboratory conditions. During this test, the geosynthetics were placed between two angular aggregate layers each confined in a square frame and a specified dynamic load was applied. After this process, the aggregates were removed from the top of the samples and they were tested using the reference test to measure the mechanical properties after the deterioration procedure. This test was performed at a temperature of $20^{\circ} \mathrm{C}$.

\subsection{Real installation test}

A test section was built to evaluate the ability of the five geosynthetics as anti-reflective cracking systems. The real installation test consisted in the installation of several sections that included the geosynthetics to simulate a rehabilitated section on a cracked road. The geosynthetics were placed on the existing road and a dense asphalt mix layer was spread and compacted on them by the usual procedure, using a vibratory roller first and then a pneumatic tyred roller. The overlay layer consisted of an AC16 mixture with a thickness of $4 \mathrm{~cm}$ and it was installed at a temperature of $160^{\circ} \mathrm{C}$. In this case, they were installed without employing a tack coat with the objective of facilitating the removal of the geosynthetics. This differed from the real installation procedure for geosynthetics in which a tack coat is employed with the objective of allowing a good bonding between the layers. After compaction and cooling of the bituminous mixture to a temperature of about $80^{\circ} \mathrm{C}$ (to avoid damaging the geosynthetics) the overlay layer was removed manually. The geosynthetics had to be recovered by pulling (Figure 2), which could cause additional damage.

\subsection{New installation procedure in laboratory}

The recovery procedure of geosynthetics from a constructed road is difficult and can damage the product. Therefore, a new experimental installation procedure with the aim of reproducing the temperature conditions and mechanical stresses during the real installation of antireflective cracking systems was developed in the laboratory. For this purpose, specimens were manufactured in the laboratory in an attempt to reproduce the installation procedure. They were composed of two layers of dense asphalt mixture (the lower layer to simulate the existing road and the upper one to simulate the overlay layer) and the geosynthetics were placed between them. After completing the manufacture of the specimens, the geosynthetics were removed for testing using the reference test procedure.

The process to manufacture the specimens was as follows: first, an AC16 Surf dense asphalt mixture layer was spread and compacted to a height of $40 \mathrm{~mm}$. When this layer had cooled, a bituminous emulsion was spread. The amount of emulsion used was that recommended by the geosynthetics' manufacturers (Table 1). After breaking of the emulsion (from $30 \mathrm{~min}$ to $1 \mathrm{~h}$ ), the geosynthetic was placed so that there were no creases.

When the geosynthetic had perfectly bonded to the lower layer, a new $40 \mathrm{~mm}$ deep asphalt layer (AC16 Surf) was spread and dynamically compacted at a temperature of $160^{\circ} \mathrm{C}$. The dynamic compaction was performed according to EN 12697-33:2003 + A1:2007 (BSI 2007), reaching $98 \%$ of the Marshall density. This procedure is commonly employed in the laboratory to prepare specimens that simulate bituminous layers.

The dimensions of the specimens were determined by the mould $\left(260 \times 410 \mathrm{~mm}^{2}\right.$ area $)$. The geosynthetic was placed so that its main direction was coincident with the largest dimension of the specimen. In this way, the longitudinal dimension of the geosynthetic coincided with 


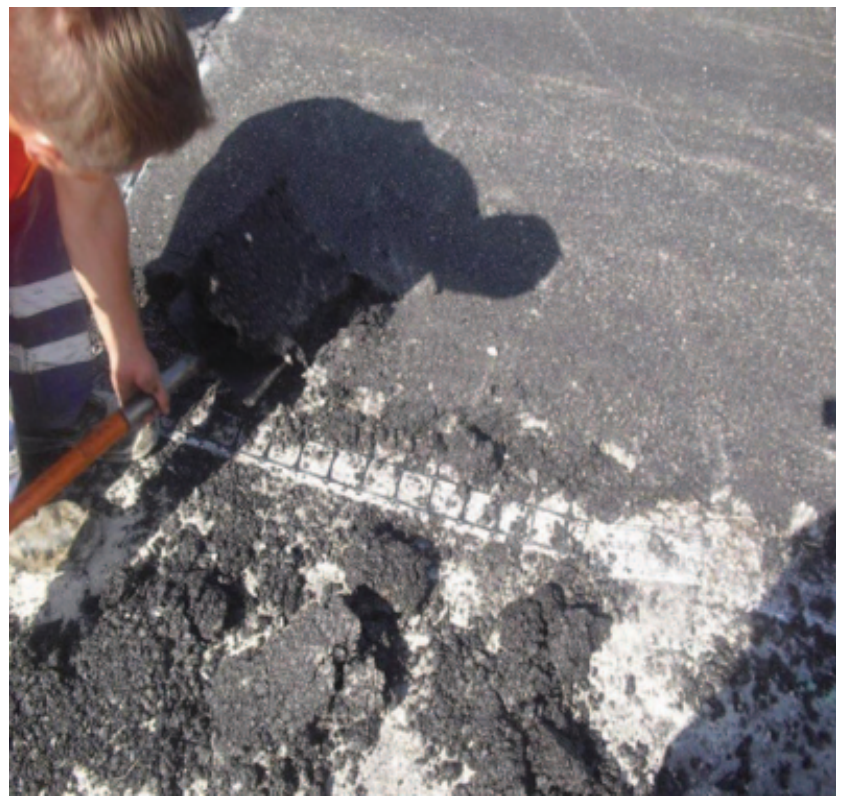

(a)

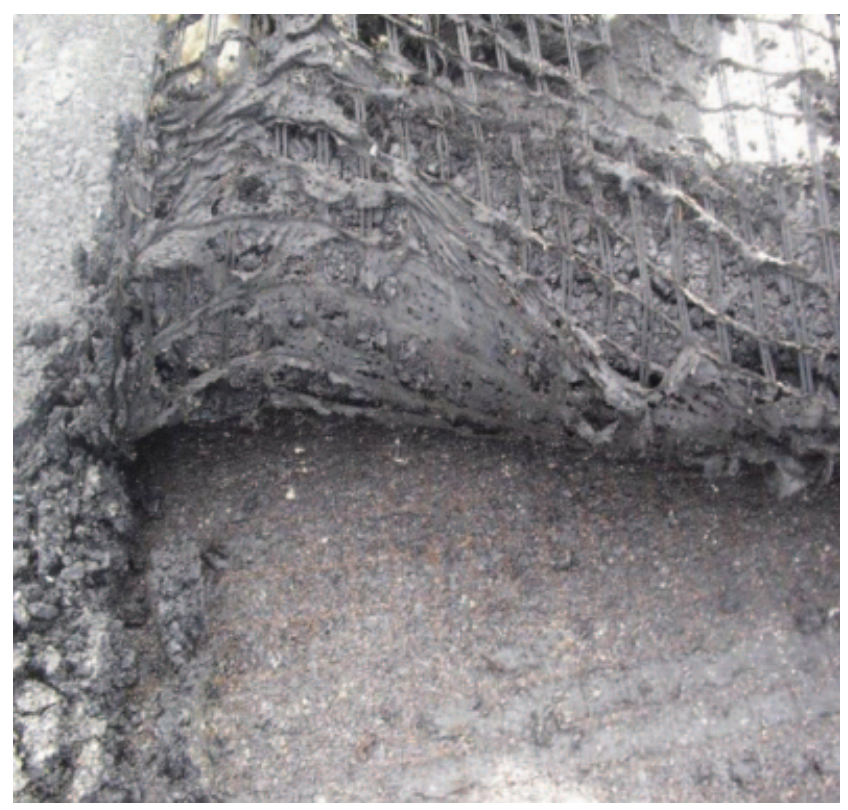

(b)

Figure 2. Test section: (a) removal of the bituminous layer, and (b) recovery of the geosynthetics

the direction of the movement of the roller compactor and the process was as similar as possible to that used for actual installation.

Finally, the specimens were left to cool at ambient temperature and the last step was the removal of the geosynthetics. For this purpose, the specimens were heated to $110^{\circ} \mathrm{C}$ and the layers were separated so that the geosynthetics could be easily extracted without causing any apparent damage (see Figure 3).

\section{RESULTS AND DISCUSSION}

Table 2 presents the statistical parameters (average value, standard deviation and coefficient of variation (CV) for comparison between tests) calculated according to the

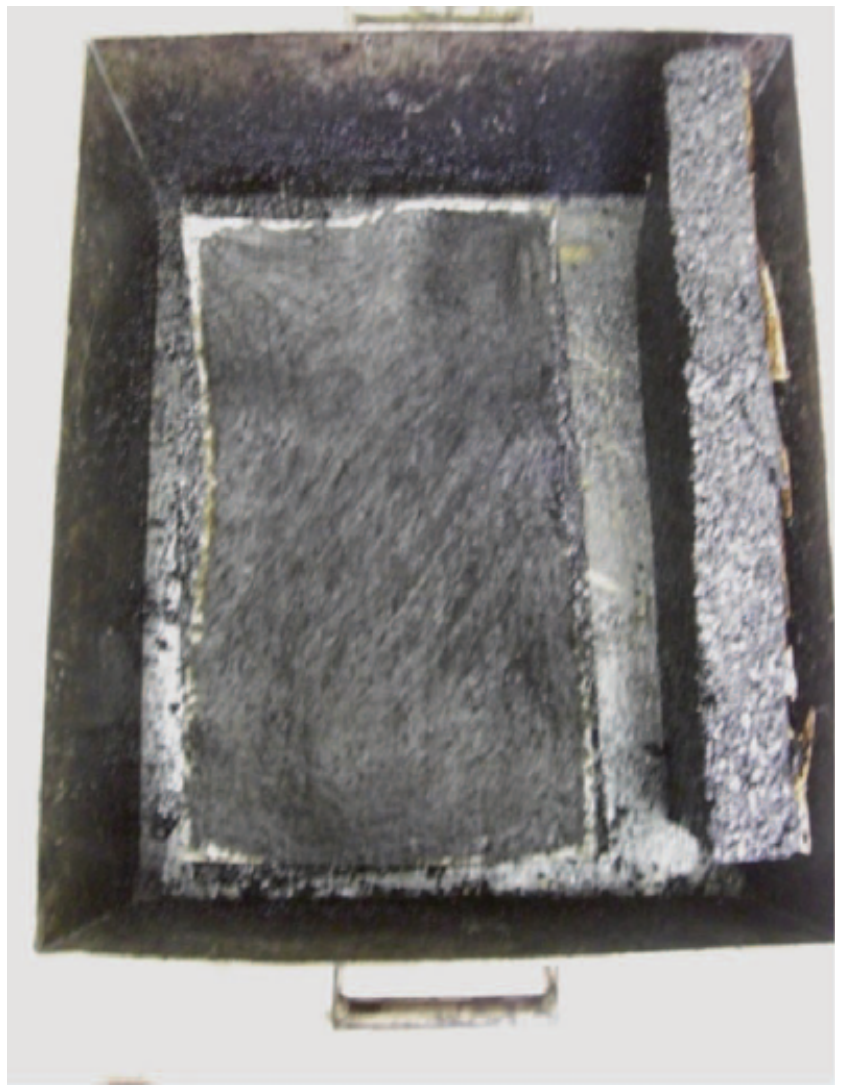

(a)

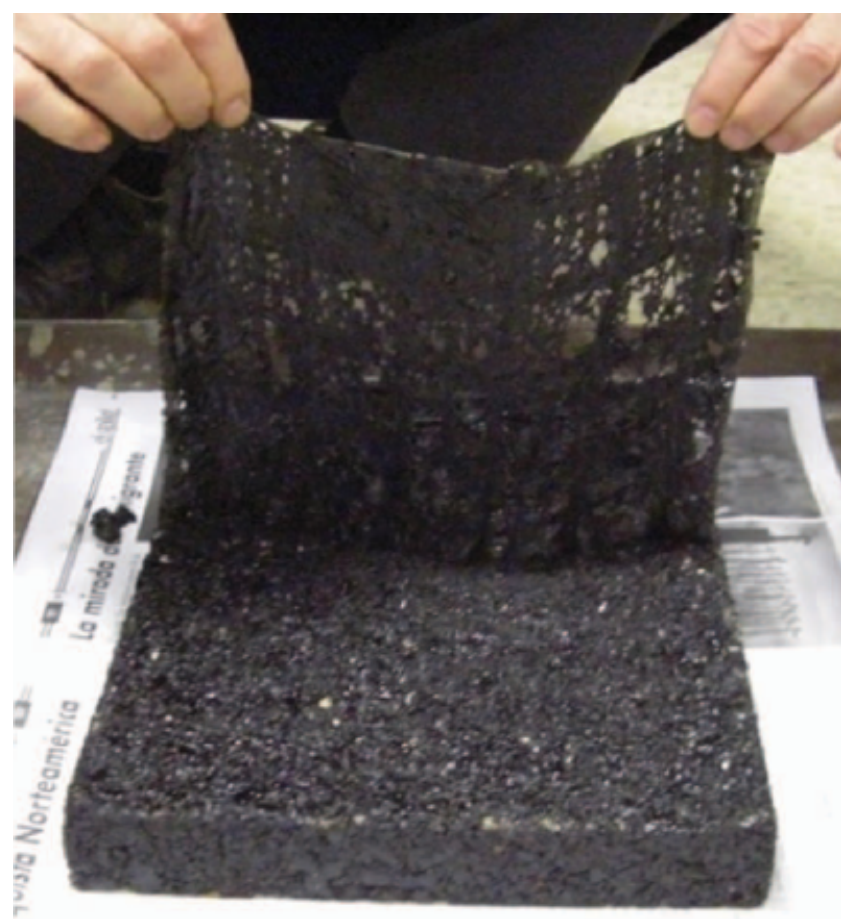

(b)

Figure 3. Laboratory test: (a) separated layers, and (b) extraction of the geosynthetic

tensile strength obtained for each geosynthetic after each applied test. From Table 2 it can be seen that the CV values obtained were higher for the results obtained after real installation and installation in laboratory tests than for the characterisation and mechanical damage tests. This 
indicates that the repeatability of results was better in the second case.

In particular, it can be observed in Table 2 that the characterisation tensile test presented the lowest $\mathrm{CV}$ with values ranging from 2 to $11 \%$. In this case the material was tested under as-received conditions and according to a standard procedure so there was no influence from variables such as the effects of aggregates and the employed asphalt mixture. The mechanical damage test presented higher $\mathrm{CV}$ values (between 1 and 17\%) than the characterisation test but the values were not as high as the real installation and installation in laboratory tests. In the mechanical damage test, only the effect of aggregates compaction was considered. The installation in laboratory test yielded CV values that ranged between 1 and $45 \%$ and the real installation test yielded the highest $\mathrm{CV}$ values (between 11 and 51\%). The difference between these results is justified by the variables involved in each process. In the installation in laboratory test the procedure is reproduced in the same form for each specimen, but in the real installation there are variables that cannot be controlled during the process, for example the compaction could not be homogeneous on the surface and the extraction procedure can cause additional damage.

In comparing the $\mathrm{CV}$ values of the different materials (Table 2) it can be seen that geosynthetics G3, G4 and G5 presented generally lower CV (range: 1 to $21 \%$ ) than geosynthetics G1 and G2 (range: 2 to 51\%). This difference may be due to the structure of the materials (see description in Section 3 and Figure 1). Geosynthetics G3, G4 and G5 had a grid structure, whereas geosynthetics G1 and G2 had a structure formed by a polypropylene nonwoven geotextile which is more prone to damage and can present a more heterogeneous behaviour. It is also important to note that geosynthetic G5 presented the lowest $\mathrm{CV}$ value. Geosynthetic G5 had a monolithic structure (see Figures 1e and $4 \mathrm{~b}$ ) and was only slightly affected by the deterioration procedures.

Table 3 presents the average value, standard deviation and $\mathrm{CV}$ of the secant modulus under a deformation of $2 \%$ obtained from the studied tests. In this case, the $\mathrm{CV}$ values were higher than those obtained for the tensile strength (Table 2). This is because the secant modulus is a nonlinear variable and its value is influenced by other variables such as strength and strain in the measuring range together with the variables associated with each test (for example, compaction energy, temperature, geosynthetics' extraction process, etc.). The observed differences between the $\mathrm{CV}$ values were similar to those discussed in Table 2 .

Complementary to Tables 2 and 3 and relative to tensile tests, Figure 5 shows the average load-elongation curves of the geosynthetics after the characterisation, mechanical damage by aggregates, real installation and installation in the laboratory tests. It can be seen that after applying the deterioration procedures described the geosynthetics present mechanical behaviour that was different from the initial behaviour (characterisation test), which was also different depending on the material and the applied procedure. For example, as can be seen in Figure 5, there

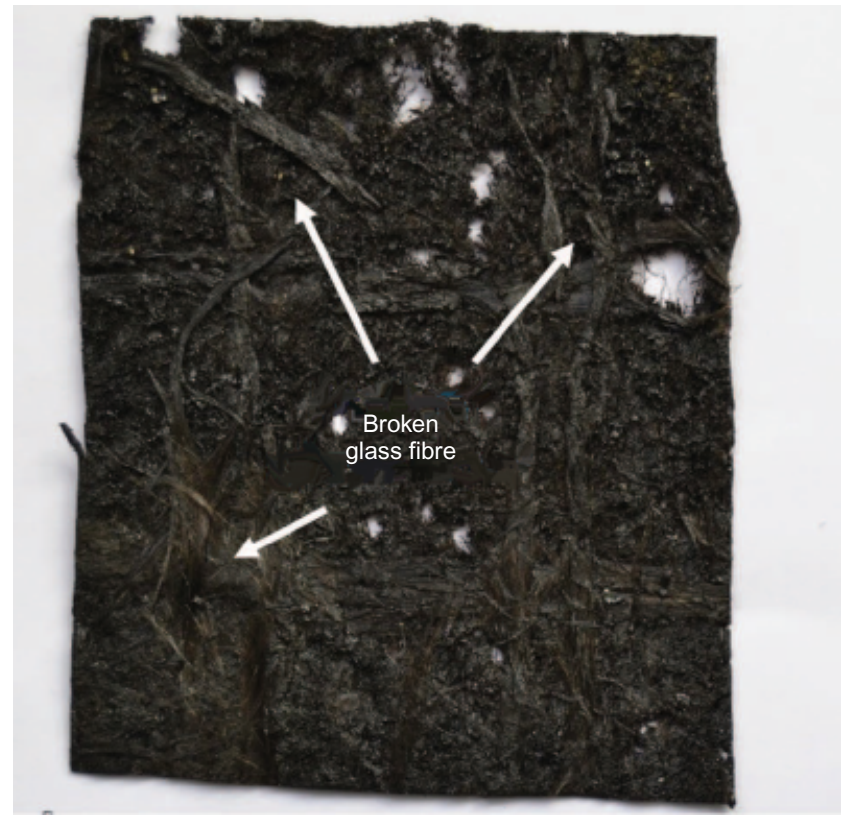

(a)

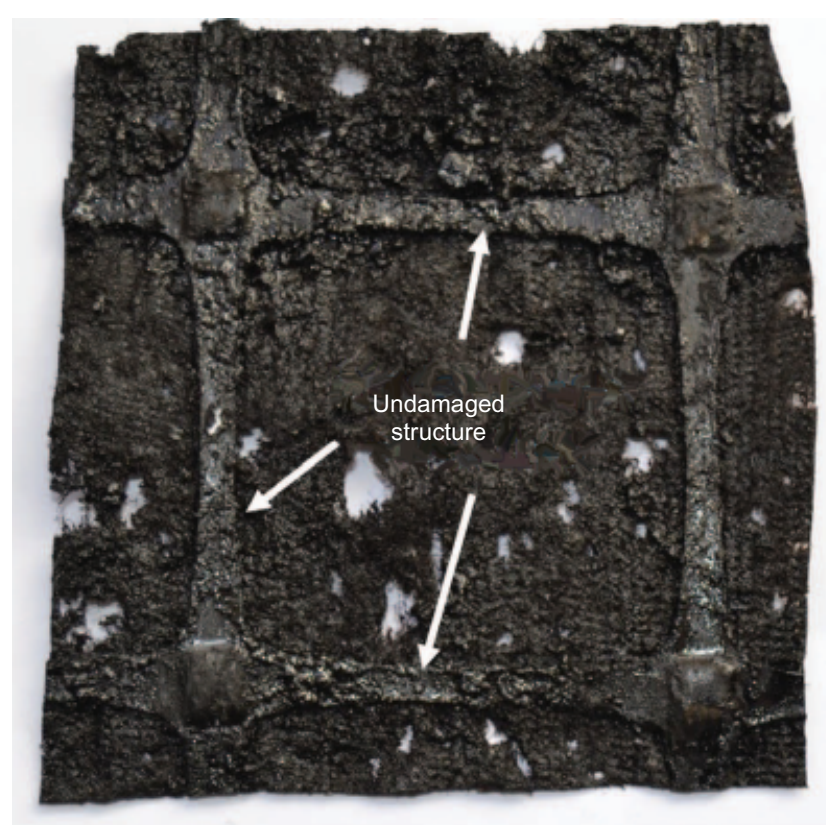

(b)

Figure 4. Deteriorated geosynthetics: (a) G2, and (b) G5 after the laboratory test

are two geosynthetics that presented extreme behaviour, see G2 and G5 in Figure 6. Geosynthetic G2 showed an important loss of its mechanical properties after the deterioration procedures had been applied. Having initially behaved as a rigid material, it presented a load-elongation curve that was more typical of an elastic material after the deterioration tests. This can be explained because geosynthetic G2 is composed of glass fibre filaments that reinforced the geotextile without any coating and they were broken after the deterioration procedures (Figure 4a). It is clear that this material was very resistant to tensile stress, but also very fragile under mechanical actions. Both factors are very important in the potential use as an anti-reflective cracking system. In addition, it is important 

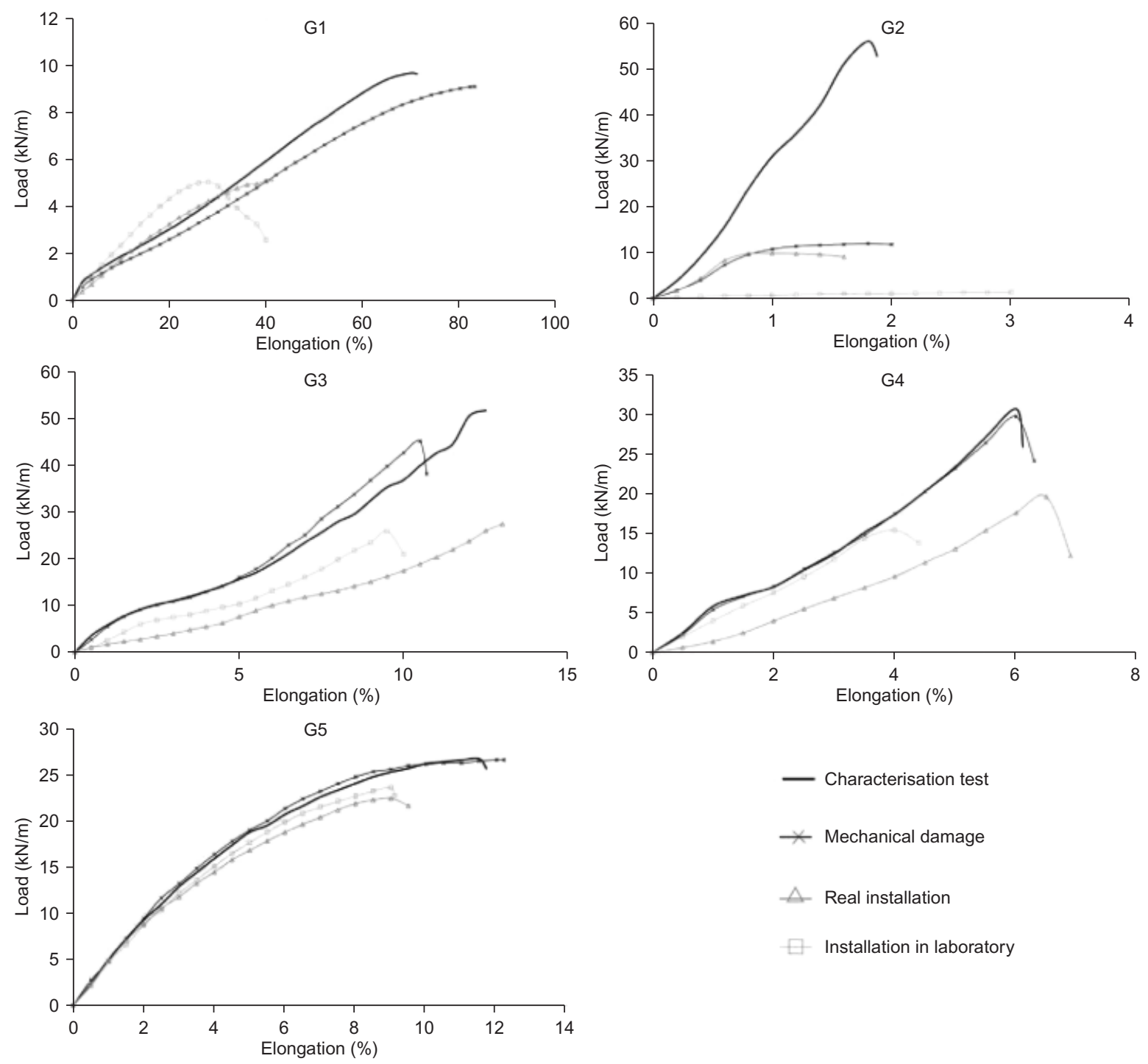

Figure 5. Load-elongation curves obtained from wide-width tensile test

to note that G2 was the only geosynthetic that suffered a significant deterioration due to the mechanical action of aggregates (Figure 5). The other four geogrids had a coated structure that can protect the resistant fibres against mechanical damage, and a visual inspection was carried out after the deterioration processes which, with the exception of G2, showed that the geosynthetics presented no appreciable damage. In contrast, G5 showed the least damage after any of the deterioration tests because of its physical characteristics, such as the thickness of the resistant elements that were approximately three times larger than those of the other materials (Table 1).

Geogrids G3 and G4 presented similar behaviour, although this depended on the deterioration test that had been applied. If the applied forces were only mechanical stresses at $20^{\circ} \mathrm{C}$, their material properties did not change. However, when these geogrids were subject to high temperatures (e.g., $150^{\circ} \mathrm{C}$ ) their measured mechanical properties decreased to values around $60 \%$ of the original values. Furthermore, in the case of G1 (nonwoven polypropylene geotextile), it was observed that all the deterioration procedures caused a decrease in its mechanical properties, indicating that G1 was susceptible to both mechanical damage and high temperature. Depending on the procedure, the retained properties varied from 40 to $75 \%$ of the original values. This result agrees with the conclusions published by Norambuena-Contreras et al. (2009).

In order to clarify the behaviours observed in Figures 5 and 6 , a comparison between the residual secant modulus values and the values obtained from the characterisation test (geosynthetic under as-received conditions) is presented in Figure 7. It can be seen from Figure 7 that the mechanical damage test by aggregates is not a representative procedure of the installation of geosynthetics in asphalt pavements, because the obtained results were very different from those obtained after the real installation and installation in laboratory tests. Moreover, it appears that in most cases the mechanical effect of aggregates on geosynthetics does not produce an important amount of deterioration. The residual secant modulus was over $80 \%$ in the case of geosynthetic G1. Geosynthetics G3, G4 and G5 retained $100 \%$ of the initial modulus and a significant decrease was only seen in the case of G2 (glass fibre geocomposite) which had a residual secant modulus of 


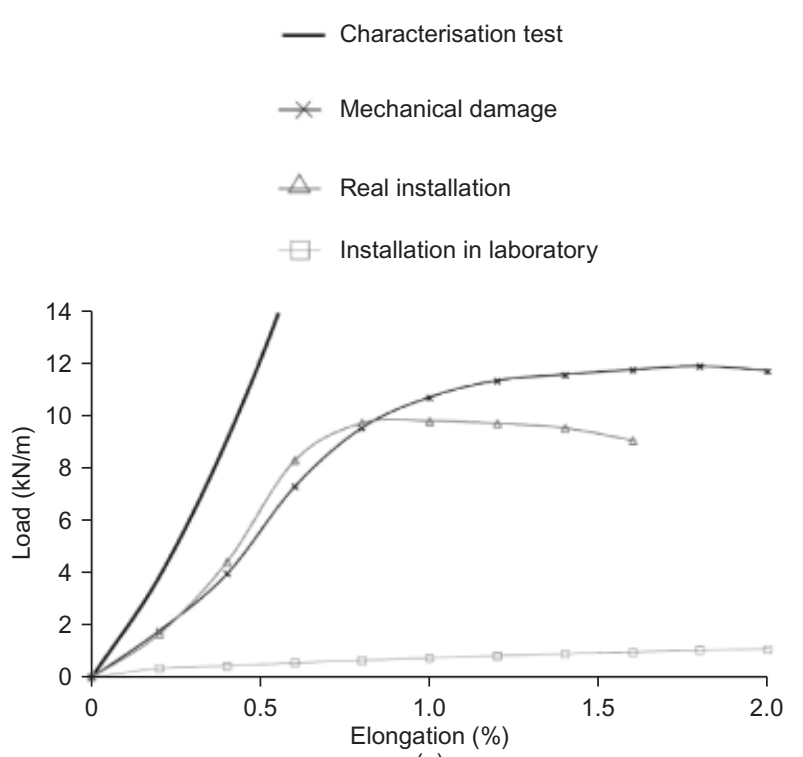

(a)

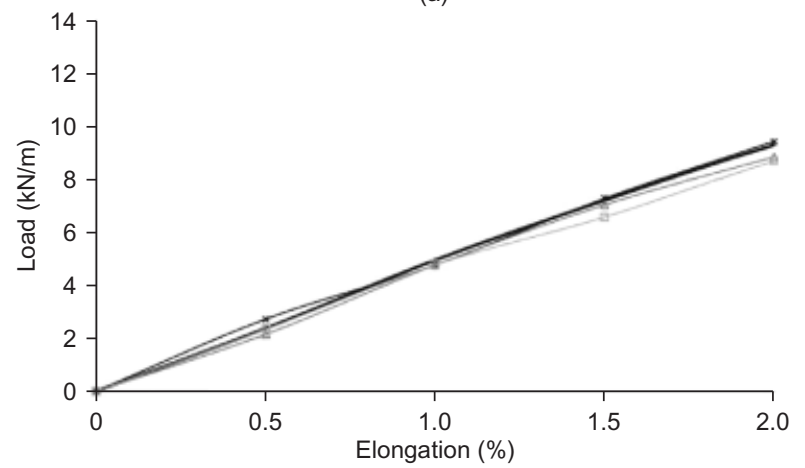

(b)

Figure 6. Initial part of the load-elongation curves obtained from wide-width tensile test: (a) G2, and (b) G5

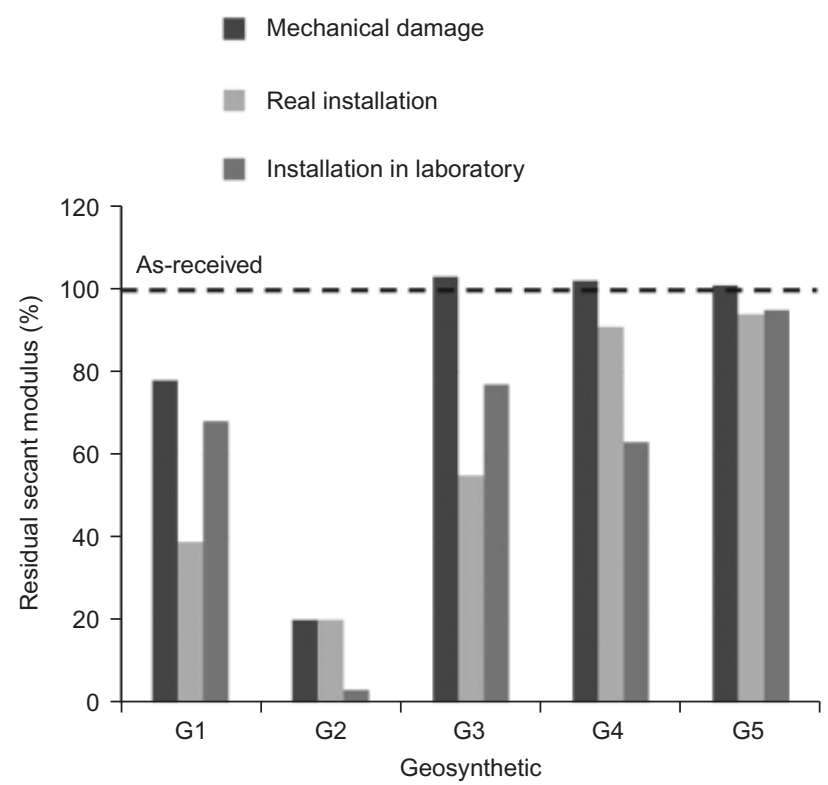

Figure 7. Residual secant modulus with regards to initial modulus in percent

$20 \%$. In contrast, after the real installation test the secant modulus was reduced although the obtained result was different in each case, varying between a residual secant modulus of $20 \%$ in the case of geosynthetic G2 and $90 \%$ for geosynthetics G4 and G5. After the new installation in laboratory test, the secant modulus behaviour was also different depending on the type of geosynthetic tested. It varied from a maximal residual modulus of $95 \%$ for material G5 to a minimal value of $5 \%$ in the case of geosynthetic G2. The other three materials had a residual modulus of over $60 \%$.

Finally, from Figure 7 a classification of the antireflective cracking systems can be defined based only on their resistance against deterioration using the procedures examined. From the least to the most resistant they can be graded as follows: G5 (stiff monolithic geogrid), G4 (polyvinyl alcohol geogrid), G3 (polyester geogrid), G1 (nonwoven polypropylene geotextile), and G2 (nonwoven polypropylene geotextile reinforced with glass fibre filaments).

\section{CONCLUSIONS}

In this study an evaluation of the damage during installation of different geosynthetics used in asphalt pavements was performed. Five geosynthetics used in asphalt pavements were studied using three different procedures, two conventional procedures and a new mechanical and thermal damage experimental procedure developed with the aim of reproducing actual installation conditions. The following conclusions are drawn, based on the results of this study.

- It was found that the real behaviour of geosynthetics as anti-reflective cracking systems depends on their resistant properties and is affected by mechanical and thermal damage during installation under a HMA. In addition, the secant modulus is the most important variable that must be taken into account for geosynthetics acting as anti-reflective cracking systems, in order to compare geosynthetics of different types and constitutive materials.

- Regarding the mechanical properties obtained as a result of the three deterioration tests applied in this study, it is concluded that the mechanical damage test (by aggregates) presented a better repeatability of results in comparison with the real installation and installation in laboratory tests. This conclusion has been proven by a comparative study between the coefficients of variation shown in Tables 2 and 3 . Furthermore, it can be observed that the repeatability of results also depends on the structure of the geosynthetics. Materials that have a grid structure present lower $\mathrm{CV}$ values than materials formed from a polypropylene nonwoven geotextile.

- In terms of the behaviour of geosynthetics after the deterioration procedures, it was observed that the behaviour differed depending on the material and the applied procedure. In addition, opposed behaviours were found: in the case of the glass fibrereinforced geotextile (G2) an important loss of mechanical properties occurred whereas the stiff monolithic geogrid (G5) showed minimal damage because of its physical characteristics. The other 
geosynthetics had different physical characteristics and presented an intermediate behaviour range between that of the $\mathrm{G} 2$ and G5 materials.

- Based on the values obtained for the resistance to deterioration of the geosynthetics when used as anti-reflective cracking systems, they have been classified from the least to the most resistant as: stiff monolithic geogrid (G5), polyvinyl alcohol geogrid (G4), polyester geogrid (G3), nonwoven polypropylene geotextile (G1), and nonwoven polypropylene geotextile reinforced with glass-fibre filaments (G2).

- $\quad$ Finally, the new damage experimental test developed in the study was shown to be an adequate method to reproduce the installation conditions of geosynthetics used as anti-reflective cracking systems in pavements. This procedure was found to be more representative of damage during installation than the mechanical damage test and easier to perform than the real installation test. Furthermore, with this procedure the variables involved can be better controlled than in the previous methods. However, to implement this new process effectively, an exhaustive experimental programme considering more variables such as the type of asphalt mixture, installation temperature and energy of compaction, should be considered for the development of a standard specification.

\section{ACKNOWLEDGEMENTS}

This investigation was supported by the research Project 'Rehabilitation of roads and highways (REHABCAR)' file number IPT-370000-2010-029, led by DRAGADOS (ACS Group), in collaboration with GEOCISA and ASFALTOS AUGUSTA among others. The project has been funded by the Ministry of Economy and Competitiveness (MINECO) within the National Plan for Scientific Research, Development and Innovation 2008-2011 (INNPACTO 2010) and the European Union under ERDF Funds (European Regional Development Fund). Finally, the authors would like to acknowledge J. Norambuena-Contreras from the Department of Civil and Environmental Engineering at University of Bío-Bío in Chile, for his valuable contributions in order to improve this paper.

\section{REFERENCES}

Allen, T. M. \& Bathurst, R. J. (1994). Characterization of geosynthetic load-strain behavior after installation damage. Geosynthetics International, 1, No. 2, 181-199.

Bathurst, R. J., Huang, B. \& Allen, T. M. (2011). Analysis of installation damage tests for LRFD calibration of reinforced soil structures. Geotextiles and Geomembranes, 29, No. 3, 323-334.

Benson, C. H., Kucukkirca, I. E. \& Scalia, J. (2010). Properties of geosynthetics exhumed from a final cover at a solid waste landfill. Geotextiles and Geomembranes, 28, No. 6, 536-546.

BSI (British Standards Institution) (2005). BS EN 13808: Bitumen and Bituminous Binders - Framework for Specifying Cationic Bituminous Emulsions. BSI, London, UK.

BSI (2007). EN 12697-33: 2003+A1: Bituminous Mixtures - Test
Methods for Hot Mix Asphalt - Part 33: Specimen Prepared by Roller Compactor. BSI, London, UK.

BSI (2008). EN 13108-1: 2006/AC: Bituminous Mixtures - Material Specifications - Part 1: Asphalt Concrete. BSI, London, UK.

Canestrari, F., Belogi, L., Ferrotti, G. \& Graziani, A. (2013). Shear and flexural characterization of grid-reinforced asphalt pavements and relation with field distress evolution. Materials and Structures, http://dx.doi.org/10.1617/s11527-013-0207-1.

Cho, S. D., Lee, K. W., Cazzuffi, D. A. \& Jeon, H. Y. (2006). Evaluation of combination effects of installation damage and creep behavior on long-term design strength of geogrids. Polymer Testing, 25, No. 6, $819-828$.

Cleveland, G. S., Button, J. W. \& Lytton, R. L. (2002). Geosynthetics in flexible and rigid pavement overlay systems to reduce reflection cracking. Texas Transportation Institute, Texas A\&M University, Austin, TX, USA, Report No. FHWA/TX-02/1777-1.

Correia, N. D. S. \& Bueno, B. D. S. (2011). Effect of bituminous impregnation on nonwoven geotextiles tensile and permeability properties. Geotextiles and Geomembranes, 29, No. 2, 92-101.

Górszczyk, J. \& Gaca, S. (2012). The influence of the carbo-glass geogrid-reinforcement on the fatigue life of the asphalt pavement structure. Archives of Civil Engineering, 58, No. 1, 97-113.

Hufenus, R., Rüegger, R., Flum, D. \& Sterba, I. J. (2005). Strength reduction factors due to installation damage of reinforcing geosynthetics. Geotextiles and Geomembranes, 23, No. 5, 401-424.

Hufenus, R., Rueegger, R., Banjac, R., Mayor, P., Springman, S. M. \& Brönnimann, R. (2006). Full-scale field tests on geosynthetic reinforced unpaved roads on soft subgrade. Geotextiles and Geomembranes, 24, No. 1, 21-37.

ISO (International Standards Organization (1998). ENV ISO 10722-1: Geotextiles and Geotextile-related Products - Procedure for Simulating Damage during Installation - Part 1: Installation in Granular Materials. ISO, Geneva, Switzerland.

ISO (2007). ISO 10722: Geosynthetics - Index Test Procedure for the Evaluation of Mechanical Damage under Repeated Loading Damage Caused by Granular Material. ISO, Geneva, Switzerland.

ISO (2008). ISO 10319:Geosynthetics - Wide-width Tensile Test. ISO, Geneva, Switzerland.

Jeon, H.-Y., Kim, S. H., Lyoo, W. S., Yoo, C. \& Koerner, G. R. (2006). Evaluation of the long-term performance of geosynthetic reinforcements from their reduction factors. Polymer Testing, 25, No. 3, 289-295.

Norambuena-Contreras, J., Barraza, D. Z., Castro-Fresno, D. \& VegaZamanillo, A. (2009). Análisis térmico de geosintéticos utilizados en la rehabilitación de pavimentos. [Thermal analysis of geosynthetics used in the rehabilitation of pavements.] Ingeniare, 17, No. 1, 95-100 (in Spanish).

Nunn, M. E. (1989). An investigation of reflection cracking in composite pavements in the United Kingdom. Proceedings of 1st Conference on Reflective Cracking in Pavements, Liege, pp. 146-153.

Pasquini, E., Bocci, M., Ferrotti, G. \& Canestrari, F. (2013). Laboratory characterisation and field validation of geogrid- reinforced asphalt pavements. Road Materials and Pavement Design, 14, No. 1, 17-35.

Paula, A. M., Pinho-Lopes, M. \& Lopes, M. L. (2012). Effect of damage during installation on the mechanical behaviour of a biaxial woven polyester geogrid. In Eurogeo 5: Proceedings of the 5th European Geosynthetics Congress, Valencia, Spain, Blanco-Fernández, M., Editor, R. B. Servicios Editoriales, S. L., Madrid, Spain, vol. 5, pp. $446-451$.

Pinho-Lopes, M. \& Lopes, M. L. (2013). Tensile properties of geosynthetics after installation damage. Environmental Geotechnics (ICE), 1, No. EG3, 161-178.

Rosete, A. J., Pinho-Lopes, M. \& Lopes, M. L. (2012). Effects of damage during installation in geocomposites mechanical and hydraulic behaviour: laboratory study. In Eurogeo 5: Proceedings of the 5th European Geosynthetics Congress, Valencia, Spain, Blanco-Fernández, M., Editor, R. B. Servicios Editoriales, S. L., Madrid, Spain, vol. 1, pp. 155-160.

Siriwardane, H., Gondle, R. \& Kutuk, B. (2010). Analysis of flexible pavements reinforced with geogrids. Geotechnical and Geological Engineering, 28, No. 3, 287-297. 
Zamora-Barraza, D., Calzada-Perez, M., Castro-Fresno, D. \& VegaZamanillo, A. (2010). New procedure for measuring adherence between a geosynthetic material and a bituminous mixture. Geotextiles and Geomembranes, 28, No. 5, 483-489.
Zamora-Barraza, D., Calzada-Perez, M. A., Castro-Fresno, D. \& VegaZamanillo, A. (2011). Evaluation of anti-reflective cracking systems using geosynthetics in the interlayer zone. Geotextiles and Geomembranes, 29, No. 2, 130-136.

The Editor welcomes discussion on all papers published in Geosynthetics International. Please email your contribution to discussion@geosynthetics-international.com by 15 June 2015. 